\title{
Erratum to: Absence of snow cover reduces understory plant cover and alters plant community composition in boreal forests
}

\author{
Juergen Kreyling • Mahsa Haei • Hjalmar Laudon
}

Published online: 21 April 2013

(c) Springer-Verlag Berlin Heidelberg 2013

Erratum to: Oecologia (2012) 168:577-587

DOI 10.1007/s00442-011-2092-z

Unfortunately, Table 3 caption was incorrectly published in the original article. The correct caption with table is given below:

Table 3 Fine root biomass (mean $\pm \mathrm{SE}$ in $\mathrm{mg} \mathrm{cm}^{-3}$ ) at $20 \mathrm{~cm}$ soil depth increments as influenced by the snow manipulations

\begin{tabular}{cllll}
\hline & $0-20 \mathrm{~cm}$ & $20-40 \mathrm{~cm}$ & $40-60 \mathrm{~cm}$ & $0-60 \mathrm{~cm}$ \\
\hline $\begin{array}{c}\text { Snow } \\
\text { removal }\end{array}$ & $2.82 \pm 0.34 \mathrm{a}$ & $0.55 \pm 0.38$ & $0.17 \pm 0.08$ & $3.53 \pm 0.80 \mathrm{a}$ \\
Control & $4.58 \pm 0.79 \mathrm{ab}$ & $0.54 \pm 0.17$ & $0.36 \pm 0.03$ & $5.49 \pm 0.54 \mathrm{ab}$ \\
Reference & $6.31 \pm 1.12 \mathrm{~b}$ & $0.85 \pm 0.27$ & $0.37 \pm 0.16$ & $7.52 \pm 1.39 \mathrm{~b}$ \\
Insulation & $4.85 \pm 0.79 \mathrm{ab}$ & $0.44 \pm 0.22$ & $0.30 \pm 0.13$ & $5.60 \pm 0.78 \mathrm{ab}$
\end{tabular}

ANOVA: treatment: $p=0.021$; depth: $p<0.001$; interaction treatment:depth: $p=0.041$. Letters in columns indicate homogenous groups according to Tukey post-hoc comparisons per depth layer if significant pairwise comparisons were found, $n=3$ per cell

The online version of the original article can be found under doi:10.1007/s00442-011-2092-z.

J. Kreyling $(\bowtie)$

Biogeography, University of Bayreuth, Bayreuth, Germany

e-mail: juergen.kreyling@uni-bayreuth.de

M. Haei

Department of Ecology and Environmental Science,

Umeå University, Umeå, Sweden

H. Laudon

Department of Forest Ecology and Management,

Swedish University of Agricultural Sciences, Umeå, Sweden 